\title{
HERBICIDAS NÃO SELETIVOS APLICADOS NA FASE DE MATURAÇÃO DO ARROZ IRRIGADO
}

\author{
Dirceu Agostinetto ${ }^{1 *}$; Nilson Gilberto Fleck ${ }^{2,4}$; Valmir Gaedke Menezes ${ }^{3}$ \\ ${ }^{1}$ Pós-Graduando do Depto. de Plantas de Lavouras - FA/UFRGS. \\ ${ }^{2}$ Depto. de Plantas de Lavoura - FA/UFRGS, C.P. 776 - CEP: 91501-970 - Porto Alegre, RS. \\ ${ }^{3}$ Instituto Rio-Grandense do Arroz - C.P. 29 - CEP: 94930-030 - Cachoeirinha, RS. \\ ${ }^{4}$ Bolsista CNPq. \\ *Autor correspondente <dirceua@vortex.ufrgs.br>
}

RESUMO: Um dos principais fatores limitantes da exploração do potencial máximo de rendimento do arroz irrigado é a interferência exercida pelo arroz vermelho, uma gramínea daninha. Botanicamente, ambos pertencem a mesma espécie (Oryza sativa L.), o que limita a utilização de herbicidas seletivos para seu controle. Com o objetivo de investigar os efeitos de herbicidas não seletivos, aplicados na fase de maturação do arroz cultivado, sobre características agronômicas da cultura, conduziu-se dois experimentos a campo nas estações de crescimento de 1997/98 e 1998/99, e avaliações em laboratório. Os tratamentos compararam os herbicidas glyphosate, glufosinate e paraquat, aplicados em duas doses e duas épocas, além do regulador de crescimento hidrazida maléica, aplicada também em duas épocas, e testemunha não tratada. Como cultivar de arroz foi utilizada a IRGA-416, de ciclo precoce. As demais práticas de manejo foram aquelas preconizadas para a cultura, a qual desenvolveu-se na presença de arroz vermelho. Avaliaram-se as características do arroz cultivado, rendimento de grãos e seus componentes, rendimento de engenho e antecipação da colheita. Os herbicidas não seletivos glyphosate, glufosinate e paraquat, quando aplicados na fase de maturação fisiológica do arroz cultivado, em geral não afetam negativamente as características agronômicas da cultura e apresentam efeitos equivalentes aos do regulador de crescimento hidrazida maléica. Variações de doses e épocas de aplicação geralmente não se diferenciam quanto à ação. A ação dessecante dos herbicidas apressa a redução da umidade dos grãos de arroz e permite antecipar a colheita. A partir do estádio em que os grãos de arroz cultivado atingem teor de umidade de 34\%, o regulador de crescimento hidrazida maléica não afeta negativamente as características da cultura.

Palavras-chave: Oryza sativa, arroz vermelho, dessecantes, hidrazida maléica

\section{NON-SELECTIVE HERBICIDES APPLIED AT THE MATURITY PHASE OF FLOODED RICE}

\begin{abstract}
One of the major limiting factor for increasing flooded rice yield potential is the interference exerted by red rice, a weedy grass. Botanically, both belong to the same species (Oryza sativa L.), which limits the utilization of selective herbicides for the control. With the objetive of investigating the effects of nonselective herbicides applied at the maturity phase of flooded rice, on agronomic characteristics of the crop, two field experiments and also laboratory evaluations were conducted during the growing seasons of 1997/98 and 1998/99. Treatments compared the herbicides glyphosate, glufosinate, and paraquat, applied at two rates and at two times, the growth regulator maleic hydrazide, applied at two times, and one check without applications of chemicals. The rice cultivar tested was IRGA-416, an early maturity variety. The management practices used were those recommended for the crop, which grew in the presence of a red rice infestation. Cultivated rice characteristics evaluated were grain yield and its components, milling yield and harvest anticipation. The nonselective herbicides glyphosate, glufosinate, and paraquat, when applied at physiological maturity stage of the cultivated rice, in general do not affect negatively the agronomic characteristics of the crop and present effects equivalent to those of the growth regulator maleic hydrazide. Differences in rates and in application times generally do not differ in relation to their actions. Desiccation action of the herbicides hastens rice grain moisture reduction and allow harvest anticipation. After the stage when flooded rice grains reach a moisture level of $34 \%$, the maleic hydrazide growth regulator does not affect negatively crop characteristics.
\end{abstract}

Key words: Oryza sativa, red rice, crop desiccation, maleic hydrazide

\section{INTRODUÇÃO}

O arroz (Oryza sativa L.) é o principal alimento para a maioria da população mundial, constituindo-se, juntamente com o trigo e o milho, nos cereais mais produzidos no mundo. A produtividade média de arroz no Rio Grande do Sul cresceu nas últimas décadas e atingiu o patamar de 5,8 $\mathrm{t} \mathrm{ha}^{-1}$ no ano de 1999 (IRGA, 1999), o que decorre, especialmente, da utilização de cultivares com alto potencial produtivo, do uso apropriado de insumos e da adoção de tecnologias modernas.

No entanto, esta produtividade ainda está aquém daquela alcançada em lavouras que adotam maior nível tecnológico e do potencial obtido nas áreas experimentais. 
Este fato deve-se, basicamente, ao controle insatisfatório das plantas daninhas, dentre as quais destaca-se 0 arroz vermelho como a espécie mais limitante ao aumento do potencial de rendimento (Souza \& Fischer, 1986). Devido ao arroz vermelho pertencer a mesma espécie botânica do arroz cultivado, seu controle torna-se difícil, custoso e apenas possível de atingir a longo prazo. Desta forma, práticas que afetem o crescimento e o desenvolvimento das plantas desta infestante e, em decorrência, sua reprodução, refletirão no tamanho do banco de sementes no solo, sendo benéficas ao longo do tempo.

Pesquisas realizadas nas últimas décadas indicam que é possível não só reduzir a produção de sementes de plantas daninhas ainda na planta-mãe, pela aplicação de produtos químicos, como também afetar sua viabilidade. Os métodos direcionados a evitar a reprodução das plantas daninhas representam potencial ideal para se reduzir, em última análise, o reabastecimento do banco de sementes no solo (Andres \& Fleck, 1994; Marín \& Bruner, 1995).

Com freqüência, herbicidas não seletivos são aplicados como auxiliares da colheita em diversas culturas, pois além de anteciparem o período de colheita, reduzem a interferência das plantas daninhas com 0 equipamento de colheita e podem melhorar a qualidade do produto colhido (Alcantara \& Wyse, 1988; Jeffery et al., 1998). De acordo com Eastin (1978), paraquat aplicado na pré-colheita de arroz cultivado, não afetou o rendimento de grãos quando as aplicações foram realizadas até 4 dias antes da colheita. Já, Gubbels et al. (1993), verificaram que o rendimento e o peso médio de grãos de linho seguiram modelo quadrático para plantas dessecadas com os herbicidas diquat, glufosinate e glyphosate quando as aplicações foram realizadas com $65,55,45,35$ e $25 \%$ de umidade nos grãos, sendo os valores maiores quanto menor foi o teor de umidade.

Por outro lado, em certas ocasiões, tem sido relatado que estes herbicidas reduzem o rendimento de grãos e afetam a viabilidade destes, restringindo sua utilização futura como sementes (Gubbels \& Dedio, 1985). Segundo Azlin \& McWhorter (1981), glyphosate não reduziu o rendimento de grãos de soja quando aspergido 7 a 12 dias antes da colheita; no entanto, quando a aplicação foi realizada 23 a 39 dias antes da colheita, o rendimento de grãos foi reduzido.

A aplicação de herbicidas dessecantes no final do ciclo da cultura do arroz, em estádio específico do desenvolvimento das plantas, poderá inviabilizar a produção de sementes pelo arroz vermelho e propiciar a antecipação de colheita do arroz cultivado. Isso pode ser vantajoso do ponto de vista econômico, desde que não prejudique a produtividade do arroz e a formação de suas sementes. Desta forma, este trabalho teve por objetivo investigar os efeitos de herbicidas não seletivos aplicados na fase de maturação do arroz cultivado, sobre diversas características agronômicas da cultura e na antecipação do período de colheita.

\section{MATERIAL E MÉTODOS}

As atividades de pesquisa foram desenvolvidas nas estações de crescimento de 1997/98 e 1998/99, sendo divididas em duas etapas. A primeira constou da realização de dois experimentos conduzidos a campo na Estação Experimental do Arroz (EEA), pertencente ao Instituto Rio-Grandense do Arroz (IRGA), localizada no município de Cachoeirinha-RS, e a segunda constou de avaliações realizadas em laboratório, junto ao Departamento de Plantas de Lavoura da Faculdade de Agronomia da Universidade Federal do Rio Grande do Sul (UFRGS), no município de Porto Alegre-RS.

O solo da área experimental da EEA/IRGA é classificado como planossolo hidromórfico, pertencendo à unidade de mapeamento Vacacaí (Embrapa Solos, 1999). A área onde foram localizados os experimentos, foi previamente submetida à operação de sistematização (em nível, com canais de irrigação, drenos e taipas), no ano de 1996, permanecendo em pousio até a instalação do primeiro experimento, na estação de crescimento 1997/98. O delineamento experimental utilizado no primeiro ano foi de blocos casualizados, com quatro repetições. Cada bloco constou de 15 tratamentos, sendo cada unidade experimental composta por uma área de $13,5 \mathrm{~m}^{2}(3 \times 4,5 \mathrm{~m})$. No segundo ano, o delineamento experimental usado foi completamente casualizado, com quatro repetições. As unidades experimentais foram compostas por áreas de $12 \mathrm{~m}^{2}(2 \mathrm{x}$ $6 \mathrm{~m})$. Além de tratamentos idênticos aos do primeiro ano, foi acrescentada uma testemunha sem infestação de arroz vermelho. Nesta, as plantas de arroz vermelho foram arrancadas manualmente nas entrelinhas logo após a emergência e, nas linhas, no estádio de alongamento do colmo.

O preparo do solo, em ambos os anos, foi realizado através do sistema convencional. Objetivando garantir o estabelecimento da população do arroz vermelho, este foi semeado a lanço na densidade aproximada de 100 sementes $\mathrm{m}^{-2}$, a incorporação das mesmas foi através de gradagem e com a passagem de rolo canelado. A população média de arroz vermelho que se desenvolveu na área experimental foi equivalente a 71 e 248 plantas $\mathrm{m}^{-2}$ para o primeiro e segundo ano, respectivamente.

Para o cultivo do arroz a campo foram seguidas as recomendações técnicas oriundas da pesquisa (Arroz Irrigado, 1997). A adubação do solo baseou-se em análise prévia das características químicas do solo. Como adubação de cobertura, utilizou-se $70 \mathrm{~kg} \mathrm{ha}^{-1}$ de nitrogênio (equivalente a $155 \mathrm{~kg} \mathrm{ha}^{-1}$ de uréia), o qual foi fracionado em duas aplicações de $35 \mathrm{~kg} \mathrm{ha}^{-1}$.

Como cultivar de arroz reagente aos tratamentos testados foi utilizada IRGA-416, a qual é de ciclo precoce ( \pm 110 dias), apresenta baixa estatura (menos de 100 $\mathrm{cm}$ ), alta capacidade de afilhamento e resistência ao acamamento. No primeiro ano, o arroz cultivado foi 
semeado no dia 17 de dezembro de 1997, em linhas afastadas $0,17 \mathrm{~m}$ entre si. Cada unidade experimental esteve formada por 18 linhas de $4,5 \mathrm{~m}$ de comprimento. No segundo ano, a semeadura foi realizada no dia 19 de novembro de 1998, em linhas afastadas 0,20 m entre si, sendo cada unidade experimental formada por dez fileiras de 6,0 m de comprimento. Em ambos os anos, a densidade de semeadura usada foi de 400 sementes $\mathrm{m}^{-2}$ e a emergência das plântulas ocorreu 7 dias após a semeadura.

Para controle das plantas daninhas (exceto arroz vermelho), aplicou-se a mistura em tanque dos herbicidas quinclorac (450 $\left.\mathrm{g} \mathrm{ha}^{-1}\right)+$ propanil (1440 $\left.\mathrm{g} \mathrm{ha}^{-1}\right)+$ pyrazosulfuron $\left(10 \mathrm{~g} \mathrm{ha}^{-1}\right), 8$ dias após a emergência (DAE) do arroz cultivado. Dois dias após este tratamento, iniciou-se a irrigação, efetuada por inundação. A lâmina de água foi mantida constante durante todo o ciclo da cultura, com altura de $10 \pm 2 \mathrm{~cm}$. A supressão da irrigação foi efetuada quando as plantas do arroz cultivado encontravam-se em maturação de colheita (umidade dos grãos de 22\%). No segundo ano, devido à ocorrência do inseto praga Oryzophagus oryzae (bicheira da raiz do arroz), aplicou-se o inseticida carbofuran (400 $\mathrm{g} \mathrm{ha}^{-1}$ ) aos 43 DAE.

Os produtos químicos (tratamentos) usados dividem-se em duas categorias: a dos herbicidas não seletivos, também referidos como dessecantes, glyphosate [N-(fosfonometil)glicina], glufosinate [ácido 2amino-4(hidroximetil-fosfinil) butanóico] e paraquat (ion 1,1'-dimetil-4,4'-bipiridinio), e a do regulador de crescimento hidrazida maléica (1,2-dihidro-3,6piridazinadiona). As aplicações dos produtos ocorreram durante um período de 5 a 6 dias. Neste período, o teor de umidade dos grãos do arroz cultivado variou de 28 (grãos duros) a 34\% (grãos pastosos), o qual coincidiu aproximadamente com a maturação fisiológica do arroz. Como padrão comparativo aos herbicidas não seletivos, utilizou-se hidrazida maléica, aplicada em duas épocas. Os tratamentos testados em ambos os experimentos estão descritos na TABELA 1.

Os tratamentos foram aplicados no horário compreendido entre 10:00 e 11:30 horas, com auxílio de pulverizador costal de precisão. Utilizaram-se bicos de jato plano do tipo "leque" e série 110.03, mantendo-se pressão constante de $\mathrm{CO}_{2}$ a $150 \mathrm{kPa}$ e velocidade de deslocamento de $3,6 \mathrm{~km} \mathrm{~h}^{-1}$, o que propiciou a aplicação de um volume de calda de $200 \mathrm{~L} \mathrm{ha}^{-1}$.

A colheita do arroz foi realizada em duas épocas. No primeiro ano, aos $99 \mathrm{DAE}$ para os tratamentos 1 a 12 e 6 dias mais tarde (aos $105 \mathrm{DAE}$ ), para os tratamentos 13,14 e 15 . No segundo ano, aos 106 DAE para os tratamentos 1 a 12 e 16, e 5 dias após (aos $111 \mathrm{DAE}$ ), para os tratamentos 13, 14 e 15. $O$ atraso na colheita dos tratamentos 13, 14 e 15 objetivou propiciar que os grãos do arroz cultivado atingissem teor de umidade apropriado para a colheita (22\%).
TABELA 1 - Tratamentos aplicados durante a fase de maturação do arroz cultivado, EEA/IRGA, Cachoeirinha, RS.

\begin{tabular}{|c|c|c|c|}
\hline \multirow[t]{2}{*}{ Tratamento testados ${ }^{1}$} & \multicolumn{2}{|c|}{ Doses } & $\begin{array}{l}\text { Umidade } \\
\text { dos }\end{array}$ \\
\hline & g i.a. ha-1 & L p.c. ha ${ }^{-1}$ & $\%$ \\
\hline 1 Glyphosate & 720 & 1,5 & 344 \\
\hline 2 Glyphosate & 1440 & 3,0 & 344 \\
\hline 3 Glyphosate & 720 & 1,5 & 305 \\
\hline 4 Glyphosate & 1440 & 3,0 & 305 \\
\hline 5 Glufosinate & 200 & 1,0 & 305 \\
\hline 6 Glufo sinate & 400 & 2,0 & 305 \\
\hline 7 Glufosinate & 200 & 1,0 & 286 \\
\hline 8 Glufo sinate & 400 & 2,0 & 286 \\
\hline 9 Paraquat $^{3}$ & 200 & 1,0 & 305 \\
\hline 10 Paraquat $^{3}$ & 400 & 2,0 & 305 \\
\hline 11 Paraquat $^{3}$ & 200 & 1,0 & 286 \\
\hline 12 Paraquat $^{3}$ & 400 & 2,0 & 286 \\
\hline 13 Hidrazida maléica & 1800 & 10,0 & 344 \\
\hline 14 Hidrazida maléica & 1800 & 10,0 & 305 \\
\hline \multicolumn{4}{|c|}{15 Testemunha sem aplicação } \\
\hline $\begin{array}{l}\text { 16 } \begin{array}{l}\text { Testemunha sem ar } \\
\text { vermelho }\end{array}\end{array}$ & & & \\
\hline
\end{tabular}

${ }^{1}$ Correspondentes aos produtos comerciais (p.c.) Roundup, Finale, Gramoxone e Fazor, respectivamente;

${ }^{2} \mathrm{Na}$ época da aplicação dos produtos químicos;

${ }^{3} \mathrm{Com}$ adição do adjuvante Agral na concentração de $0,1 \% \mathrm{v} / \mathrm{v}$;

${ }^{4}$ Arroz cultivado em estádio de grãos pastosos a duros e arroz vermelho em estádio de emissão de panículas;

${ }^{5}$ Arroz cultivado em estádio de grãos duros e arroz vermelho em estádio de floração plena;

${ }^{6}$ Arroz cultivado em estádio de grãos duros e arroz vermelho em estádio de grãos leitosos no terço superior das panículas.

As variáveis esterilidade de espiguetas e número de grãos por panícula, foram obtidas através da contagem das espiguetas estéreis e número de grãos formados, respectivamente, em uma amostra de dez panículas, coletadas aleatoriamente na área útil de cada unidade experimental. O peso médio dos grãos foi obtido através da pesagem de cinco subamostras de 100 grãos de cada unidade experimental. $O$ rendimento de grãos foi obtido colhendo-se as panículas nas áreas úteis de $6,5 \mathrm{~m}^{2}(3 \times 2,17 \mathrm{~m})$ e $6,88 \mathrm{~m}^{2}(4,3 \times 1,6 \mathrm{~m})$ de cada unidade experimental para o primeiro e o segundo ano, respectivamente. Para determinação do rendimento de engenho, utilizou-se um engenho de provas (tipo Suzuki), sendo a avaliação efetuada 88 dias após a colheita (DAC) em ambos os anos. O rendimento de engenho dos grãos de arroz foi avaliado a partir de duas amostras de $100 \mathrm{~g}$ para cada unidade experimental.

Os dados coletados foram submetidos à análise de covariância (utilizando-se como covariável o número de colmos de arroz vermelho $\mathrm{m}^{-2}$ ) através do teste $\mathrm{F}$. No segundo ano, devido ao fato de não se constatar 
significância na análise de covariância, procedeu-se análise de variância, através do teste $F$. No caso de se constatar significância estatística para tratamentos, foram procedidas comparações entre as médias dos tratamentos utilizando-se o teste de Duncan ao nível de $5 \%$ de probabilidade. Para a variável esterilidade de espiguetas, cujos valores são expressos em percentagem, realizou-se transformação dos dados através do arco seno da raiz quadrada de cada observação.

\section{RESULTADOS E DISCUSSÃO}

Para a variável esterilidade de espiguetas das panículas do arroz determinada no primeiro ano de pesquisa (TABELA 2), a comparação entre os produtos testados e a testemunha revelou que os tratamentos com paraquat $\left(400 \mathrm{~g} \mathrm{ha}^{-1}\right)$ e glufosinate $\left(200 \mathrm{~g} \mathrm{ha}^{-1}\right)$, aplicados na segunda época, mais glyphosate (1440 $\mathrm{g} \mathrm{ha}^{-1}$ ) aplicado na primeira época, diferiram da testemunha, apresentando esterilidade superior. Entre tratamentos herbicidas, geralmente não houve diferenças para esta variável, inclusive em relação ao produto padrão hidrazida maléica. No segundo ano, a esterilidade de espiguetas (TABELA 2) não diferiu entre os tratamentos com produtos químicos e a testemunha que não recebeu aplicação, cujos valores situaram-se entre 56 e $76 \%$. No entanto, todos estes tratamentos apresentaram maiores índices de esterilidade do que a testemunha sem presença de arroz vermelho. A maior esterilidade de espiguetas verificada no segundo ano, deveu-se a maior infestação de arroz vermelho, cuja população média foi $349 \%$ superior a do primeiro ano. A elevada população de arroz vermelho, acrescido da diferença de estatura entre os tipos de planta, pode ter provocado um efeito protetor (guarda chuva) sobre as plantas de arroz cultivado, provavelmente impedindo que parte do produto químico aspergido chegasse até a cultura. Isso faz supor que a elevada esterilidade de espiguetas observada, inclusive na testemunha sem aplicação, foi causada, principalmente, pela interferência do arroz vermelho e não devido ao efeito dos produtos químicos aplicados.

No primeiro ano, o número de grãos por panícula (TABELA 2) em geral foi estatisticamente similar para os diferentes tratamentos. Contudo, a quantidade de grãos nas panículas das plantas de arroz oriundas do tratamento com paraquat (400 $\left.\mathrm{g} \mathrm{ha}^{-1}\right)$, na segunda época, foi menor do que no padrão hidrazida maléica aplicada na segunda época. Para a mesma variável no segundo ano, a testemunha com presença de arroz vermelho apresentou valor $61,7 \%$ inferior a testemunha sem presença da infestante. Em relação à testemunha com presença de arroz vermelho, não houve diferença significativa entre tratamentos.

TABELA 2 - Efeito de produtos químicos aplicados na fase de maturação do arroz cultivado sobre esterilidade de espiguetas por panícula, número de grãos por panícula e peso de 1000 grãos da cultivar e arroz IRGA-416, EEA/IRGA, Cachoeirinha, RS.

\begin{tabular}{|c|c|c|c|c|c|c|c|c|c|}
\hline \multirow{2}{*}{\multicolumn{2}{|c|}{ Tratamentos testados }} & \multirow{2}{*}{ Doses } & \multirow{2}{*}{$\begin{array}{l}\text { Umidade } \\
\text { dos grãos }\end{array}$} & \multicolumn{2}{|c|}{ Esterilidade } & \multicolumn{2}{|c|}{ Grãos por panícula } & \multicolumn{2}{|c|}{ Peso de 1000 grãos } \\
\hline & & & & $1997 / 98$ & $1998 / 99$ & $1997 / 98$ & $1998 / 99$ & $1997 / 98$ & $1998 / 99$ \\
\hline & & \multicolumn{2}{|l|}{ g i.a. ha-1 } & \multicolumn{2}{|c|}{-------- \% --------- } & \multicolumn{2}{|c|}{------- no ------- } & \multicolumn{2}{|c|}{ 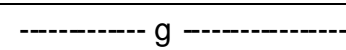 } \\
\hline 1 & Glyphosate & 720 & 34 & $25 b c^{2}$ & $59 a$ & $48 a b$ & $30 \mathrm{~b}$ & $26,1 \mathrm{abc}$ & $26,7 \mathrm{bc}$ \\
\hline 2 & Glyphosate & 1440 & 34 & $36 a b$ & $61 \mathrm{a}$ & $45 a b$ & $29 \mathrm{~b}$ & $25,5 \mathrm{abcd}$ & $27,0 \mathrm{bc}$ \\
\hline 3 & Glyphosate & 720 & 30 & $23 \mathrm{bc}$ & $74 \mathrm{a}$ & $39 a b$ & $47 \mathrm{~b}$ & $25,9 a b c$ & $25,9 \mathrm{c}$ \\
\hline 4 & Glyphosate & 1440 & 30 & $26 \mathrm{bc}$ & $56 a$ & $45 a b$ & $45 \mathrm{~b}$ & $25,6 \mathrm{abc}$ & $28,1 \mathrm{~b}$ \\
\hline 5 & Glufo sinate & 200 & 30 & $21 \mathrm{bc}$ & $68 a$ & $54 \mathrm{a}$ & $34 \mathrm{~b}$ & $25,9 a b c$ & $28,0 \mathrm{bc}$ \\
\hline 6 & Glufosinate & 400 & 30 & $28 a b c$ & $67 \mathrm{a}$ & $43 a b$ & $32 b$ & $25,1 \mathrm{abcd}$ & $26,8 \mathrm{bc}$ \\
\hline 7 & Glufo sinate & 200 & 28 & $35 a b$ & $56 a$ & $39 a b$ & $38 \mathrm{~b}$ & $24,9 \mathrm{~cd}$ & $28,3 b$ \\
\hline 8 & Glufo sinate & 400 & 28 & $23 b c$ & $64 a$ & $44 a b$ & $42 \mathrm{~b}$ & $25,4 \mathrm{abcd}$ & $28,3 b$ \\
\hline 9 & Paraquat & 200 & 30 & $29 a b c$ & $66 \mathrm{a}$ & $44 a b$ & $35 \mathrm{~b}$ & $25,0 \mathrm{bcd}$ & $27,6 \mathrm{bc}$ \\
\hline 10 & Paraquat & 400 & 30 & $28 a b c$ & $65 \mathrm{a}$ & $43 a b$ & $29 b$ & $25,2 \mathrm{abcd}$ & $27,8 \mathrm{bc}$ \\
\hline 11 & Paraquat & 200 & 28 & $29 a b c$ & $76 a$ & $38 a b$ & $51 \mathrm{~b}$ & $24,9 \mathrm{~cd}$ & $28,6 b$ \\
\hline 12 & Paraquat & 400 & 28 & $47 \mathrm{a}$ & $71 \mathrm{a}$ & $34 \mathrm{~b}$ & $39 \mathrm{~b}$ & $24,1 d$ & $28,1 \mathrm{~b}$ \\
\hline 13 & Hidrazida maléica & 1800 & 34 & $25 \mathrm{bc}$ & $59 a$ & $45 a b$ & $30 \mathrm{~b}$ & $26,4 a b$ & $27,4 \mathrm{bc}$ \\
\hline 14 & Hidrazida maléica & 1800 & 30 & $27 \mathrm{bc}$ & $61 \mathrm{a}$ & $53 a$ & $31 \mathrm{~b}$ & $26,2 a b c$ & $27,5 \mathrm{bc}$ \\
\hline 15 & \multicolumn{3}{|c|}{ Testemunha sem aplicação } & $16 c$ & $66 \mathrm{a}$ & $46 a b$ & $31 \mathrm{~b}$ & 26,6 a & $27,3 \mathrm{bc}$ \\
\hline 16 & \multicolumn{3}{|c|}{ Testemunha sem arroz vermelho } & -- & $18 b$ & -- & $81 \mathrm{a}$ & -- & $32,4 \mathrm{a}$ \\
\hline \multicolumn{4}{|c|}{ Coeficiente de variação (\%) } & 22,7 & 18,0 & 23,6 & 36,9 & 3,5 & 4,5 \\
\hline
\end{tabular}

${ }^{1} \mathrm{Na}$ época de aplicação dos produtos químicos;

${ }^{2}$ Médias seguidas pela mesma letra, comparadas nas colunas, não diferem pelo teste de Duncan a $5 \%$. 
Com relação ao peso de 1000 grãos (TABELA 2) verificou-se, no primeiro ano, que os tratamentos com paraquat a $200 \mathrm{~g} \mathrm{ha}^{-1}$, em ambas as épocas de aplicação, e paraquat a $400 \mathrm{~g} \mathrm{ha}^{-1}$ e glufosinate $200 \mathrm{~g}$ ha $^{-1}$ na segunda época, apresentaram valores inferiores ao da testemunha, situando-se, em média, 7,1\% abaixo desta. Em geral, estes mesmos tratamentos também produziram grãos de menor peso em relação ao padrão hidrazida maléica aplicada na primeira época, mas não diferiram da segunda aplicação deste produto. No segundo ano da pesquisa, para a variável peso de 1000 grãos (TABELA 2), a testemunha com presença de arroz vermelho apresentou valor $15,7 \%$ inferior ao da testemunha sem presença da infestante, devido ao efeito de interferência que a invasora ocasionou ao arroz cultivado. De modo geral, não houve diferenças entre os tratamentos, sendo que nenhum daqueles que recebeu aplicação de herbicida não seletivo diferiu do padrão hidrazida maléica nem tampouco da testemunha não tratada. Porém, verificou-se tendência de ocorrer maiores diferenças entre tratamentos no primeiro ano do que no segundo ano de pesquisa.

Os resultados obtidos no primeiro ano de pesquisa para a variável peso médio de grãos assemelham-se aos obtidos por Eastin (1978). O autor verificou que paraquat aplicado 10 dias antes da colheita reduziu o peso médio de grãos do arroz cultivado; porém, não apresentou efeito quando as aplicações foram realizadas em período mais próximo da colheita. Por outro lado, Clarke (1981) não observou diferenças no peso médio de grãos de trigo pela dessecação précolheita com glyphosate, paraquat e diquat quando os teores de umidade nos grãos eram de 39 e $43 \%$. Resultados semelhantes foram observados por Gigax \& Burnside (1976).

No primeiro ano da pesquisa, a umidade de grãos do arroz cultivado, por ocasião da colheita, variou em função dos tratamentos utilizados (TABELA 3). Na maioria dos casos, os teores de umidade foram inferiores ao da testemunha que não recebeu aplicação, exceto para hidrazida maléica na primeira época, cujo teor de umidade se equivaleu, e para glyphosate na dose de 720 $\mathrm{g} \mathrm{ha}^{-1}$ aplicado na segunda época, cujo teor de umidade foi superior ao da testemunha. Em geral, os tratamentos que utilizaram os produtos paraquat e glufosinate causaram quedas maiores da umidade de grãos por ocasião da colheita do arroz. Em média, os tratamentos com paraquat reduziram em 5,0 pontos o grau de umidade dos grãos em comparação aos com glyphosate; já em relação aos de hidrazida maléica esta diferença foi de 5,4 pontos percentuais.

No segundo ano de pesquisa, a umidade de grãos do arroz cultivado, por ocasião da colheita, foi maior na testemunha sem presença de arroz vermelho

TABELA 3 - Efeito de produtos químicos aplicados na fase de maturação do arroz cultivado sobre umidade dos grãos na colheita e rendimento de grãos da cultivar de arroz IRGA-416, EEA/IRGA, Cachoeirinha, RS.

\begin{tabular}{|c|c|c|c|c|c|c|c|c|c|}
\hline \multicolumn{2}{|c|}{ Tratamentos testados } & \multirow{2}{*}{$\begin{array}{c}\text { Doses } \\
\text { g i.a. ha-1 }\end{array}$} & \multirow{2}{*}{$\begin{array}{l}\text { Umida- } \\
\text { de dos } \\
\text { grãos }^{1}\end{array}$} & \multicolumn{2}{|c|}{$\begin{array}{l}\text { Umidade dos grãos na } \\
\text { colheita }\end{array}$} & \multicolumn{4}{|c|}{ Rendimento de grãos } \\
\hline & & & & \multicolumn{2}{|c|}{------- \% --------- } & $\mathrm{kg} \mathrm{ha}^{-1}$ & $\%$ & $\mathrm{~kg} \mathrm{ha}^{-1}$ & $\%$ \\
\hline 1 & Glyphosate & 720 & 34 & $20,8 c^{2}$ & $17,8 \mathrm{~cd}$ & $1851 \mathrm{ab}$ & 65,4 & $101 \mathrm{c}$ & 70 \\
\hline 2 & Glyphosate & 1440 & 34 & $20,3 d$ & 17,1 cdef & $1861 a b$ & 65,7 & 215 bc & 132 \\
\hline 3 & Glyphosate & 720 & 30 & $24,9 a$ & 16,8 def & $1876 a b$ & 66,2 & $90 \mathrm{c}$ & 55 \\
\hline 4 & Glyphosate & 1440 & 30 & $20,3 d$ & 16,7 def & $2343 a b$ & 82,7 & $318 \mathrm{bc}$ & 195 \\
\hline 5 & Glufo sinate & 200 & 30 & $20,1 d$ & $17,7 \mathrm{~cd}$ & $2223 a b$ & 78,5 & $204 \mathrm{bc}$ & 125 \\
\hline 6 & Glufo sinate & 400 & 30 & $15,5 \mathrm{~h}$ & 16,8 def & $1958 a b$ & 69,1 & $189 \mathrm{bc}$ & 116 \\
\hline 7 & Glufo sinate & 200 & 28 & $17,7 f$ & 17,3 cde & $1692 b$ & 59,7 & $165 \mathrm{bc}$ & 101 \\
\hline 8 & Glufo sinate & 200 & 28 & $19,2 \mathrm{e}$ & $18,3 \mathrm{bc}$ & $1886 a b$ & 66,6 & $387 \mathrm{bc}$ & 237 \\
\hline 9 & Paraquat & 200 & 30 & $17,0 \mathrm{~g}$ & $16,0 f$ & $1909 a b$ & 67,4 & $270 \mathrm{bc}$ & 166 \\
\hline 10 & Paraquat & 400 & 30 & $14,5 \mathrm{i}$ & 16,3 ef & $2312 a b$ & 81,6 & $284 \mathrm{bc}$ & 174 \\
\hline 11 & Paraquat & 200 & 28 & $18,1 \mathrm{f}$ & 16,9 def & $2039 a b$ & 72,0 & $532 b$ & 326 \\
\hline 12 & Paraquat & 400 & 28 & $16,6 \mathrm{~g}$ & $19,3 \mathrm{~b}$ & 1797 b & 63,4 & $319 \mathrm{bc}$ & 196 \\
\hline 13 & Hidrazida maléica & 1800 & 34 & $22,6 b$ & $13,2 \mathrm{gh}$ & $2129 a b$ & 75,2 & $172 \mathrm{bc}$ & 106 \\
\hline 14 & Hidrazida maléica & 1800 & 30 & $21,3 c$ & $14,3 \mathrm{~g}$ & $2657 a b$ & 93,8 & $243 \mathrm{bc}$ & 149 \\
\hline 15 & \multicolumn{3}{|c|}{ Testemunha sem aplicação } & $22,3 b$ & $12,5 \mathrm{~h}$ & $2832 \mathrm{a}$ & 100,0 & $163 \mathrm{bc}$ & 100 \\
\hline 16 & \multicolumn{3}{|c|}{ Testemunha sem arroz vermelho } & -- & $21,9 a$ & -- & -- & $4325 a$ & 2653 \\
\hline \multicolumn{4}{|c|}{ Coeficiente de variação (\%) } & 2,4 & 4,6 & 28,2 & & 48,8 & \\
\hline
\end{tabular}

${ }^{1} \mathrm{Na}$ época de aplicação dos produtos químicos;

${ }^{2}$ Médias seguidas pela mesma letra, comparadas nas colunas, não diferem pelo teste de Duncan a $5 \%$. 
do que nos demais tratamentos. Entre tratamentos com herbicidas não seletivos, as diferenças não foram acentuadas e, na maioria dos casos, eles foram estatisticamente equivalentes (TABELA 3). Contudo, paraquat, na dose maior e aplicado na segunda época, em geral apresentou maior teor de umidade do que os demais tratamentos. Já, os menores teores de umidade nos grãos foram medidos no tratamento testemunha que não recebeu aplicação de produto químico e naqueles tratados com hidrazida maléica.

A menor umidade de grãos na colheita, determinada na testemunha sem aplicação e nos tratamentos que receberam hidrazida maléica, deveu-se ao maior período de condução do experimento a campo (em função da testemunha sem presença de arroz vermelho apresentar umidade de grãos elevada durante um maior período de tempo). Além disso, a alta infestação de arroz vermelho e a diferença de estatura entre a cultura e a invasora, assim como a manutenção da irrigação até a data de colheita, favoreceram a formação de microclima úmido no interior da comunidade, o que explicaria a constatação de plantas de arroz cultivado já mortas por ocasião da segunda época de colheita. Estes fatores também podem justificar o menor teor de umidade nos grãos na colheita observado na segunda estação de crescimento, comparativamente à primeira.

Com relação ao rendimento de grãos (TABELA 3), no primeiro ano verificou-se que os tratamentos com glufosinate a $200 \mathrm{~g} \mathrm{ha}^{-1}$ e paraquat a $400 \mathrm{~g} \mathrm{ha}^{-1}$, aplicados na segunda época, apresentaram produtividades inferiores à da testemunha sem aplicação; porém, eles não diferiram dos demais tratamentos. Aqueles dois tratamentos produziram, respectivamente, rendimentos 40,3 e $36,6 \%$, menores do que o da testemunha. Isso foi decorrência da maior esterilidade de espiguetas (TABELA 2) e do menor peso médio de grãos (TABELA 2) verificado em ambos os tratamentos, comparativamente à testemunha sem aplicação.

No segundo ano, a testemunha sem presença de arroz vermelho apresentou rendimento de grãos superior aos demais tratamentos químicos e à testemunha sem aplicação de produto (TABELA 3). Constatou-se que a interferência exercida pelo arroz vermelho reduziu em $94,2 \%$ a produtividade do arroz quando são comparadas as duas testemunhas, e redução de $96,2 \%$ quando a testemunha sem infestação é comparada à produtividade média dos tratamentos que receberam produtos químicos. No entanto, não se verificaram diferenças significativas entre os tratamentos com aplicação de herbicidas não seletivos e os padrões com hidrazida maléica e a testemunha, provavelmente devido ao elevado coeficiente de variação verificado. Por exemplo, em relação à testemunha infestada por arroz vermelho, os tratamentos com glyphosate nas menores doses, em ambas as épocas de aplicação, reduziram o rendimento de grãos em 30 e $45 \%$, respectivamente. O baixo rendimento de grãos observado na testemunha sem infestação de arroz vermelho na segunda estação de crescimento, deveu-se à competição exercida pelas plantas de arroz vermelho que se encontravam na linha, já que estas somente foram retiradas no estádio de alongamento do colmo.

Comparando-se as duas estações de crescimento, verifica-se ter ocorrido queda generalizada do rendimento de grãos na segunda estação de crescimento, devido à presença de maior população de arroz vermelho. O grau de prejuízo causado pelo arroz vermelho é atribuído a sua habilidade competitiva com o arroz cultivado, podendo causar redução de até $82 \%$ no rendimento, segundo Sankula et al. (1997). Contudo, neste trabalho a redução de produtividade foi cerca de $95 \%$, em função da elevada população que se estabeleceu na área experimental no segundo ano de pesquisa. Na prática, isso inviabilizaria a produção comercial e a operação de colheita do arroz cultivado.

Caso as sementes atinjam o máximo conteúdo de matéria seca antes delas e das plantas se apresentarem suficientemente secas para permitir a colheita mecânica, então a aplicação de produtos dessecantes por ocasião da maturação fisiológica resultará em antecipação da colheita (Durigan \& Carvalho, 1980). As sementes de arroz da cultivar IRGA416, quando em competição com arroz vermelho, atingem peso máximo de grãos ao redor de 24 dias após o florescimento, o que caracteriza sua maturação fisiológica. Esta condição, na qual os grãos apresentam $30 \%$ de umidade, define a época adequada para aplicação de herbicida não seletivo visando antecipação da colheita (Fleck et al., 1999).

Na primeira estação de crescimento, glyphosate nas épocas e doses testadas possibilitou antecipar a colheita, em média, 2 dias. Já os tratamentos com glufosinate e paraquat permitiram antecipar a colheita, em média, 5 e 6 dias, respectivamente. Este efeito pode ser atribuído aos diferentes modos de ação dos produtos químicos testados, em que glyphosate apresenta ação sistêmica e glufosinate e paraquat ação de contato (Ahrens, 1994). Na segunda estação de crescimento, a presença de elevada população de arroz vermelho, associada ao atraso na colheita devido ao maior teor de umidade de grãos no tratamento sem presença de arroz vermelho, provocou morte das plantas de arroz cultivado, dificultando a determinação exata do período de antecipação da colheita.

Além da antecipação da colheita, os herbicidas não seletivos, por apresentarem efeito dessecante, favorecem a instalação antecipada de espécies forrageiras ou de cobertura de solo, devido à redução da relação $\mathrm{C} / \mathrm{N}$ da resteva e conseqüente menor imobilização do nitrogênio pelos microrganismos do solo, aumentando sua disponibilidade para a cultura posterior (Aita \& Ros, 1996). Por outro lado, ocorre perda do potencial de uso da resteva pela ação dessecante dos 
herbicidas, o que inviabiliza seu emprego para pastoreio com bovinos, prática comumente utilizada pelos orizicultores no Estado.

Para sorgo, foi verificado (Gigax \& Burnside, 1976) que glyphosate e paraquat anteciparam a colheita em 5 e 7 dias, respectivamente; enquanto a dessecação da cultura efetuada à umidade de $25 \%$ nos grãos antecipou a colheita em apenas 2 dias. Também, Bovey \& McCarty (1965) observaram que herbicidas dessecantes apressaram a data de colheita do sorgo em aproximadamente 10 dias quando foram aplicados nos níveis de 40 e $50 \%$ de umidade nos grãos. Por outro lado, a diminuição da umidade dos grãos foi menos rápida quando as plantas foram tratadas com os grãos apresentando menores níveis de umidade (30\%). Já, Clarke (1981) verificou em 3 anos de pesquisa que glyphosate, diquat e paraquat, aplicados na pré-colheita do trigo, não modificaram significativamente o teor de umidade dos grãos em relação ao tratamento testemunha.

A diminuição do potencial do rendimento de grãos da cultura devido a herbicidas aplicados em período pós-maturação fisiológica depende, fundamentalmente, do estádio em que se encontram os grãos na época de aplicação. Pesquisa conduzida para investigar a influência dos herbicidas não seletivos glyphosate, glufosinate e paraquat, aplicados na fase reprodutiva da soja, revelou que o rendimento de grãos foi severamente reduzido por todos os herbicidas quando eles foram aplicados no estádio R5; entretanto, apenas glyphosate não reduziu o rendimento quando foi aplicado no estádio R6, e nenhum dos herbicidas reduziu o rendimento da soja quando foram aplicados em estádio mais tardio (Ratnayake \& Shaw, 1992). Por outro lado, a dessecação pré-colheita do trigo com os herbicidas glyphosate, diquat e paraquat não afetou o rendimento de grãos quando as aplicações foram realizadas com teor de umidade nos grãos de $43 \%$ ou menos (Clarke, 1981).

Para rendimento de grãos inteiros, verificou-se que as doses de glyphosate aplicadas na primeira época, apresentaram valores superiores ao tratamento testemunha (TABELA 4). Com relação ao rendimento de grãos quebrados, constatou-se que os tratamentos com glyphosate, aplicados na primeira época, originaram menores valores do que o da testemunha. Entre tratamentos com herbicidas não seletivos, em geral não houve diferenças para estas duas variáveis; do mesmo modo, eles não diferiram do produto padrão (hidrazida maléica). Para renda do benefício, nenhum dos tratamentos que recebeu produto químico diferiu da testemunha que não recebeu aplicação.

TABELA 4 - Efeito de produtos químicos aplicados na fase de maturação do arroz cultivado sobre rendimento de grãos inteiros e de grãos quebrados e renda do benefício da cultivar de arroz IRGA-416, UFRGS, Porto Alegre, RS.

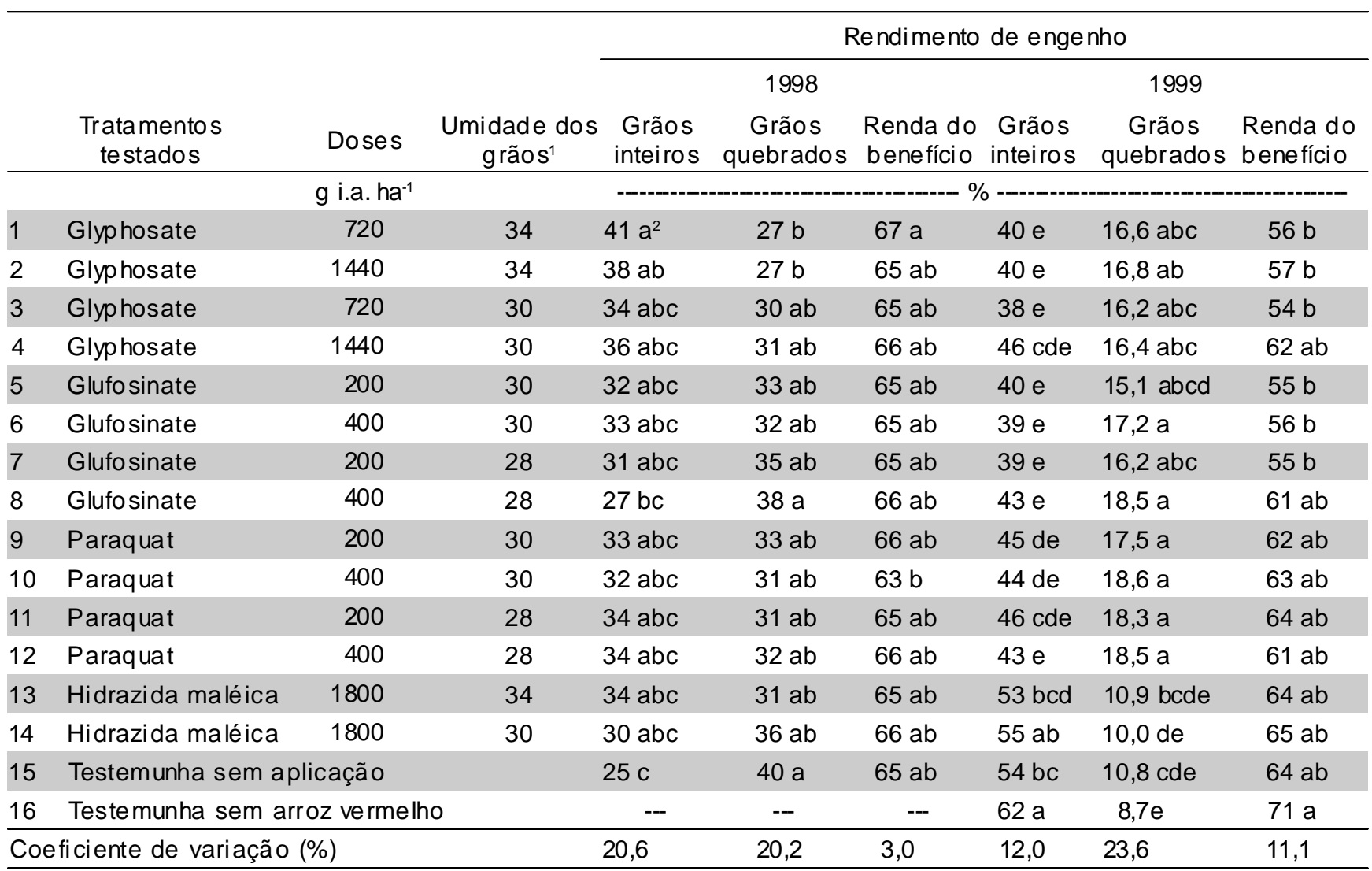

${ }^{1} \mathrm{Na}$ época de aplicação dos produtos químicos;

${ }^{2}$ Médias seguidas pela mesma letra, comparadas nas colunas, não diferem pelo teste de Duncan a $5 \%$. 
$\mathrm{Na}$ segunda estação de crescimento, os resultados para rendimento de engenho (TABELA 4) mostraram que a testemunha sem infestação de arroz vermelho apresentou o maior valor absoluto para rendimento de grãos inteiros, valor quase $15 \%$ superior ao da testemunha infestada. Para as variáveis grãos quebrados e renda de benefício, não houve diferenças entre as testemunhas com ausência e presença de arroz vermelho. O menor valor absoluto para rendimento de grãos quebrados ocorreu na testemunha sem infestação de arroz vermelho. Para nenhuma das três variáveis relativas ao rendimento de engenho houve diferenças significativas entre as duas testemunhas e o tratamento padrão com hidrazida maléica aplicada na segunda época.

Para nenhuma das três variáveis do rendimento de engenho foram constatadas diferenças entre os tratamentos que receberam aplicações de herbicidas não seletivos. No entanto, para grãos inteiros, estes tratamentos originaram menores valores do que o padrão hidrazida maléica aplicada na segunda época. Já, para grãos quebrados ocorreu efeito inverso, em que, geralmente, verificou-se menor valor para o padrão hidrazida maléica aplicada na segunda época. Para renda de benefício, nenhum dos tratamentos que recebeu aplicação de herbicidas não seletivos diferiu do padrão hidrazida maléica. O rendimento de grãos inteiros, no segundo ano foi, em média, $34,6 \%$ superior ao do primeiro ano. Por outro lado, o rendimento de grãos quebrados foi, em média, $51,4 \%$ inferior no segundo ano, comparativamente ao primeiro ano.

A elevada infestação de arroz vermelho que se estabeleceu no segundo ano, associada a maior altura de suas plantas em relação às do arroz cultivado, provocou um efeito protetor (guarda chuva), provavelmente impedindo que parte do produto químico aspergido atingisse plenamente as camadas inferiores de folhas. Este fato, permite pressupor que os resultados obtidos na segunda estação de crescimento sobre as características do arroz cultivado devam-se, basicamente, à interferência exercida pelo arroz vermelho e à interceptação da pulverização que sua folhagem possa ter provocado, afetando a precisa quantificação dos efeitos dos produtos químicos aplicados.

No presente trabalho não foram realizadas análises de resíduos dos herbicidas nos grãos de arroz, determinação que apresenta importância decisiva, pois a presença de resíduos destes agrotóxicos nos grãos pode inviabilizar sua utilização na alimentação e, conseqüentemente, minimizar o emprego deste método de manejo. Dentre os herbicidas dessecantes utilizados, somente paraquat já é recomendado para tal finalidade na cultura do arroz, apresentando intervalo de segurança de 7 dias entre aplicação e colheita do cereal (Rodrigues \& Almeida, 1995). O herbicida glufosinate ainda não está recomendado para uso na cultura do arroz, porém, para a cultura da soja, o intervalo de segurança previsto é de 10 dias. Já, o herbicida glyphosate não apresenta intervalo de segurança definido, pois não é recomendado para dessecação de culturas.

\section{CONCLUSÕES}

Os herbicidas não seletivos glyphosate, glufosinate e paraquat, quando aplicados na fase de maturação fisiológica do arroz cultivado, em geral não afetam negativamente as características agronômicas da cultura e apresentam efeitos equivalentes aos do regulador de crescimento hidrazida maléica.

A ação dessecante dos herbicidas glyphosate, glufosinate e paraquat aumenta a perda de umidade dos grãos de arroz e permite antecipar a colheita entre 2 e 6 dias.

Para os herbicidas não seletivos testados, as variações de doses e épocas de aplicação geralmente não exercem ação diferencial sobre as características da cultura;

A partir do estádio em que os grãos de arroz cultivado atingem $34 \%$ de umidade, o produto hidrazida maléica não apresenta efeitos negativos sobre as características agronômicas da cultura.

Elevada infestação de arroz vermelho afeta negativamente a maioria das características agronômicas do arroz, causando perda quase total da produtividade de grãos.

\section{REFERÊNCIAS BIBLIOGRÁFICAS}

AHRENS, W.H. (Ed.) Herbicide handbook. 7.ed. Champaign: Weed Science Society of America, 1994. 352p.

AITA, C.; ROS, C.O. da. Efeito de espécies de inverno na cobertura do solo e fornecimento de nitrogênio ao milho em plantio direto. Revista Brasileira de Ciência do Solo, v.20, p.135-140, 1996.

ALCANTARA, E.N.; WYSE, D.L. Glyphosate as harvest aid for corn (Zea mays). Weed Technology, v.2, p.410-413, 1988.

ANDRES, A.; FLECK, N.G. Efeitos de herbicidas aplicados no período reprodutivo sobre o crescimento inicial de plantas daninhas na geração seguinte. Planta Daninha, v.12, p.70-77, 1994.

ARROZ irrigado: recomendações técnicas da pesquisa para o Sul do Brasil. 4.ed. Itajaí: EPAGRI; EMBRAPA, CPACT; IRGA, 1997. 80p.

AZLIN, W.R.; MCWHORTER, C.G. Preharvest effects of applying glyphosate to soybeans (Glycine max). Weed Science, v.29, p.123-127, 1981.

BOVEY, R.W.; MCCARTY, M.K. Effect of preharvest desiccation on grain sorghum. Crop Science, v.5, p.523-526, 1965.

CLARKE, J.M. Effect of diquat, paraquat and glyphosate on preharvest drying of wheat. Canadian Journal of Plant Science, v.61, p.909-913, 1981.

DURIGAN, J.C.; CARVALHO, N.M. Aplicação, em pré-colheita, de dessecante em duas cultivares de soja [Glycine max (L.) Merril]: I. Efeitos imediatos sobre a germinação e produção de sementes. Planta Daninha, v.6, p.108-115, 1980.

EASTIN, E.F. Preharvest desiccation of rice with paraquat. Crop Science, v.18, p.1068-1070, 1978.

EMBRAPA SOLOS. Sistema brasileiro de classificação de solos. Rio de Janeiro, 1999. 412p. 
FLECK, N.G.; AGOSTINETTO, D.; SILVA, P.R.F. da; MEROTO JR., A.; VIDAL, R.A. Duração e taxa do enchimento de grãos, rendimento de grãos e componentes do rendimento da cultivar de arroz IRGA-416 afetados pela presença de arroz vermelho. In: CONGRESSO BRASILEIRO DE ARROZ IRRIGADO, 1.; REUNIÃO DA CULTURA DO ARROZ IRRIGADO, 23., Pelotas, 1999. Anais. Pelotas: Embrapa Clima Temperado, 1999. p.494-496.

GIGAX, D.R.; BURNSIDE, O.C. Chemical desiccation of grain sorghum. Agronomy Journal, v.68, p.645-649, 1976.

GUBBELS, G.H.; BONNER, D.M.; KENASCHUK, E.O. Effect of swathing and desiccation time on seed yield and quality of flax. Canadian Journal of Plant Science, v.73, p.397-404, 1993.

GUBBELS, G.H.; DEDIO, W. Desiccation of sunflower with diquat. Canadian Journal of Plant Science, v.65, p.841-847, 1985.

IRGA. Divisão de Assistência Técnica e Extensão. Acompanhamento de colheita do arroz irrigado - Safra 1998/99. Porto Alegre, 1999. 8p.

JEFFERY, E.M.; SHAW, D.R.; BARRENTINE, W.L. Herbicide combinations for preharvest weed desiccation in early maturing soybean (Glycine max). Weed Technology, v.12, p.157-165, 1998
MARÍN, A.R.; BRUNER, H.M. Control químico del arroz colorado. In: INSTITUTO NACIONAL DE TECNOLOGIA AGROPECUARIA. ESTACIÓN EXPERIMENTAL AGROPECUARIA CORRIENTES. Proyecto arroz: campaña 1994-95. s.I., 1995. p.55-62.

RATNAYAKE, S.; SHAW, D.R. Effects of harvest-aid herbicides on soybean (Glycine max) seed yield and quality. Weed Technology, v.6, p.339-344, 1992.

RODRIGUES, B.N.; ALMEIDA, F.S. de. Guia de herbicidas. 3.ed. Londrina: Ed. dos Autores, 1995. 675p.

SANKULA, S.; BRAVERMAN, M.P.; JODARI, F.; LINSCOMBE, S.D.; OARD, J.H. Evaluation of glufosinate on rice (Oryza sativa) transformed with the BAR gene and red rice (Oryza sativa). Weed Technology, v.11, p.70-75, 1997.

SOUZA, P.R. de; FISCHER, M.M. Arroz vermelho: danos causados à lavoura gaúcha. Lavoura Arrozeira, v.39, p.1920, 1986.

$\overline{\text { Recebido em } 05.06 .00}$ 